\title{
LIBS TOOL TO DIAGNOSE THE EGYPTIAN DETERIORATED WALL PAINTINGS DURING LASER CLEANING PROCESS, AN EXPERIMENTAL STUDY
}

\author{
Brania, A. ${ }^{\text {, }}$ Imam, H. ${ }^{2}$, Elsayed, K. ${ }^{3}$ \& Elrashdy R. ${ }^{2}$ \\ ${ }^{1}$ Conservation Dept., Faculty of Archaeology, Cairo Univ., ${ }^{2}$ National Institute of laser Enhanced Sciences, \\ Cairo Univ. ${ }^{3}$ Physics Dept., Faculty of Sciences, Cairo Univ. Egypt-e-mail: atefbran@yahoo.com
}

\begin{abstract}
The wall painting surfaces represent the main challenge for the laser cleaning techniques. The objective of this work has been the study of the laser cleaning technique when applied to wall paintings. In particular, this study has been devoted to understanding how the characteristics of the laser apparatus and its specific use are linked with the nature of the substances to be removed from the painting. A number of artificially wall paintings were selected with paint layers that were composed of different pigments and covered with different dirties. In this work the feasibility of laser cleaning for the removal of dirties from the wall painting surfaces using Q-switch Nd:YAG laser operating at two different wavelengths: in the infra-red and in the visible (1064 and $532 \mathrm{~nm})$ is presented. The effectiveness of the cleaning process was monitored by following the disappearance from the LIBS spectra of the deterioration aspects elements during successive laser shots. The aim of this work is focus on the definition of the experimental boundary conditions in which laser cleaning can be safely applied in cleaning of the deteriorated wall paintings.
\end{abstract}

Keywords: Wall painting, LIBS, Cleaning, diagnose, laser

\section{Introduction}

Commonly used methods of surface cleaning in conservation of art works are based on mechanical or chemical techniques which are individually selected by experienced conservators. These traditional methods are very difficult to control. Cleaning of delicate objects, diverse from the point of view of materials composition needs not only extended expert appraisements of used substances, but also minimization of possible damages, always present in the case of mechanical cleaning. Chemical reagents show similar interactions in the conservation of paintings, where chemicals penetrate technological painting layers and causes permanent, difficult to analyze, cross-sectional alterations. Conservation practice shows the necessity of frequent treatments of sophisticated objects with complex technological structures and individual preservation states, resulting from the influence of diverse external factors, as well as changes in original material on construction itself. Application of conventional conservation methods is limited and difficult. Moreover, every detail requires individual, predetermined cleaning parameters. Application of 
laser technique gives possibility of almost full control of the encrustation removal process at the surface of art works. Selective and precise interaction of the light beam is a fundamental advantage of non-invasive treatment of more or less tightly connected unwanted surface layers. Specific properties of lasers, decrease of system costs, and reduction of dimensions of laser cleaning systems have contributed to increasing applications of lasers in conservation, particularly during recent the ten to fifteen years [1][2][3]. Laser cleaning must be considered as an advanced tool applied in cases where traditional techniques may be inadequate. Nevertheless, extreme care should be taken for the optimization of the operational parameters in order to ensure the absence of any negative effects induced on the artwork. It should be pointed out in this place that laser cleaning of historical objects is still far from being as popular as the conventional techniques, being employed in an increasing, but relatively small number of restoration interventions, mainly applied to stone substrates. Even if the last generation of laser systems has improved the understanding of their effects and their engineering, laser cleaning is not yet a mature technology for earlier restoration tests, there is also lack of indepth knowledge of the basic laserartwork interaction mechanisms [3][4][5][6]. There is still also a lack of diagnostic devices providing qualitative and quantitative information during the laser cleaning intervention. Application of laser radiation in physico-chemical surface analyses and structural objects investigations, have started simultaneously with development of laser cleaning systems. In the face of increasing interest in laser cleaning and diagnostic systems, important is acquaintance of the conservation community with the fundamental advantages and shortcomings of laser radiation in treatment and analysis of matter. Material investigations have shown that main conservation cleaning problem with stone sculptures exposed to atmospheric pollution is the preservation of delicate patinas. This historical superficial layer can be lost, as a result, to the use of non-laser, aggressive, not fully controlled cleaning methods. Laser cleaning as a method of restoring works of art has undergone successful testing in the course of the last two decades and has become widely used in solving many problems that have great practical significance. The most substantial results in this case were achieved in the restoration of stone monuments. It was demonstrated that laser processing has high efficiency and a number of other advantages in this area by comparison with traditional technologies [1]. The examples described in the literature of the successful use of lasers in carrying out restoration work on certain well-known monuments, including sculptures and the façades of historical buildings, $[2][3][4][5][6][7] m a k e$ it possible to speak today of the wide use of laser methods in the restoration of stone in many countries of the world. Although a number of successful applications have been reported, laser cleaning has its own disadvantages in practice [8]. For example overexposure to the laser pulse may easily result in substrate damage due to the high energy density of the laser beam This is may lead to fatal faults in art conservation and a loss of yield in the surface cleaning and loss of the artwork integrity. Meanwhile underexposure can have residual contaminations on the surface. The whole surface has to be cleaned by scanning the laser beam if a substrate much larger than the laser spot is to be treated. Since the contaminations are not uniformity distributed on the substrate surface and if the surface is 
uneven or irregular, some areas of the substrate may suffer damage while others still have residual contamination if the laser irradiation condition are applied over the whole surface during the laser scanning. Therefore in-process monitoring is required to control the laser cleaning process. Since laser cleaning of a wide variety of artworks has been strongly developing in the last decade, LIBS has become an effective method for on-line monitoring of the cleaning process itself. During contaminants removal from the object surface, the emitted spectra change due to change of elemental composition of the ablated layer. This change can be used to understand the causes of contamination and also to avoid undesired over-cleaning of the object itself. Laser cleaning, with the aid of on-line. LIBS monitoring, has been employed to remove extraneous coatings of various kinds, including dark encrustations from marble, terracotta, stone and glass artworks due to exposure to air pollutants [9][10][11][12], protective and conservative coatings from canvas paintings and synthetic mimicking materials $\quad[13][14][15][16][17[18]$, corroded layers from metal objects [19][20], dirt (dust and pen and pencil traces) from historical paper documents [21][22], pencil and pen marks on alabaster and marble statues in a standoff configuration [23], and patinas on surfaces of historical buildings [24]. The most appealing features of LIBS applications in the field of cultural heritage analysis are mainly the following: its micro-destructiveness, with ablated sample portions on the order of fractions of micrograms and induced damage virtually invisible to the naked eye; its potential for fast multi-elemental analysis and capability of simultaneous detection of major and trace elements; its equipment, easily compactable into portable instruments for in situ analyses of piece of arts that cannot be removed from museums or excavation sites, or of historical buildings and wall paintings. Besides being a powerful technique to control the removal of layers due to aging and pollution of artworks, LIBS is among the few techniques able to provide multielemental depth-profiling of intrinsically multi-layered samples, such as ceramics, paintings and frescoes, resulting at the same time only micro-destructive. This potential has been exploited, often coupled with Raman spectroscopy that provides complementary molecular information for dating and provenance studies [25][26] and for pigment identification in a number of different painted artworks, including ceramics [25][27], icons and miniatures [26][27], painted plasters [28], polychromes on wood [29], artistic prints, wall paintings of historical buildings and historical parchment [30][31][32]. The objective of this work has been the study of the laser cleaning technique when applied to wall paintings. In particular, this study has been devoted to understanding how the characteristics of the laser apparatus and its specific use are linked with the nature of the substances to be removed from the painting. A number of artificial wall paintings "models" were selected with paint layers that were composed of different pigments applied with the most common media in Egyptian wall painting. The laser used was a Nd:YAG laser operating in Q-switch. The laser could emit at two different wavelengths: in the infra-red and in the visible (1064 and $532 \mathrm{~nm}$ ). The main objective of the work was to determine the optimum working conditions for the substances to be removed, through the establishment of laser parameters such as the wavelength, the repetition rate and the energy density. LIBS technique was used as an effective method for on-line monitoring of the cleaning process during the deterioration aspects "encrustation" removal from the object surface, by monitoring the emitted spectra change due to change of elemental composition of the ablated layer. 


\section{Experimental Section}

\subsection{Wall painting models description:}

Models of the most common wall painting "components and stratigraphy" in Egypt were prepared at the laboratory. On one hand, limestone and gypsum were used as a support and plaster coat consequently followed by application the most common pigments in tempera technique. On the other hand three kind of the most common pigment (red or brown "Hematite $\alpha-\mathrm{Fe}_{2} \mathrm{O}_{3}$ ", yellow "goethite $\alpha$-FeOOH".[33] and black "carbon black C") [34], in the Egyptian wall painting were used, after well

preparation. Glue, Arabic Gum and Albumin were used as the common binder of the Egyptian pigments, in the wall painting. Only one binder was selected for application with every pigment in the model. After the models preparation, an artificial and concentrated layer of the most common deterioration aspects "dirties" mud mixed with gypsum; soot, wax, and gypsum were added on the experimental models surfaces, fig. (1).

\subsection{Artificial ageing (Heating-drying cycles)}

On one hand, it is usually considered that artificial ageing has a great advantage because of rapidly obtained results in comparison with natural weathering. It is important to define the laboratory parameters of the cyclic artificial ageing [35] of the painting materials in order to find out the relation between artificial climatic ageing and natural weathering thus affording the opportunity to predict the real durability of the painting under natural ageing conditions. On the other hand, temperature fluctuation causes the deformations in the painted rendering's external layer. The air temperature fluctuation in Upper Egypt is considering the most common factor of deterioration of the wall painting.
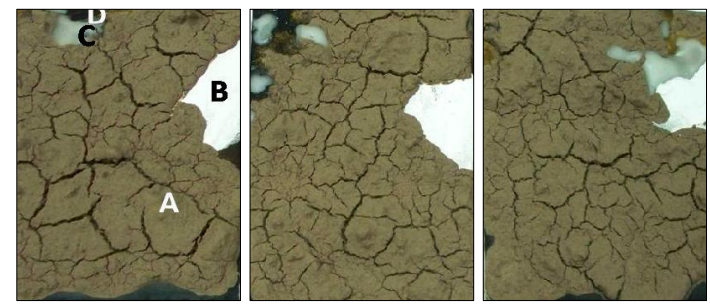

Figure (1) the wall painting models after adding the deterioration aspects: a) mixed mud with gypsum, b) gypsum, c) wax and d) soot and aging.

\subsection{Methodology}

\subsubsection{Mechanical cleaning}

The first step for removing the concentrated layer of dirties was the
Depending on that, artificial heating cycles elected as the main parameter. The experimental models with its artificial dirties have been prolonged to artificial ageing cycles in a climatic chamber. In the climatic chamber the following temperature regimes have been applied 15 cycle in $65^{\circ} \mathrm{C}(16$ hour in the climatic chamber) - followed by 8 hours in the normal condition 15 cycle in $120{ }^{\circ} \mathrm{C}$ with the same procedure. Petrie dish full of water was in the climatic chamber for the humidity, imitating the natural weather as possible as we can. The deterioration aspects became whiter than before was the only notice after the artificial ageing cycles, fig. (2).
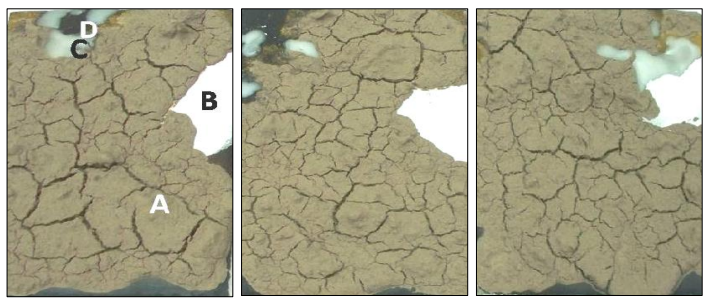

Figure (2) the wall painting models after the artificial ageing cycles: a) mixed mud with gypsum, b) gypsum, c) wax and d) soot.

mechanical cleaning. One hand different kinds of soft brushes, 
scalpels...etc, were used, with locally wetting by distilled water and ethanol $1: 1$, fig. (3). On the other hand removing the surfaces incrustation was not so difficult except gypsum and wax.
The mechanical cleaning was stopped after removing the majority of incrustation to start laser cleaning experiments, as a chemical cleaning alternative.

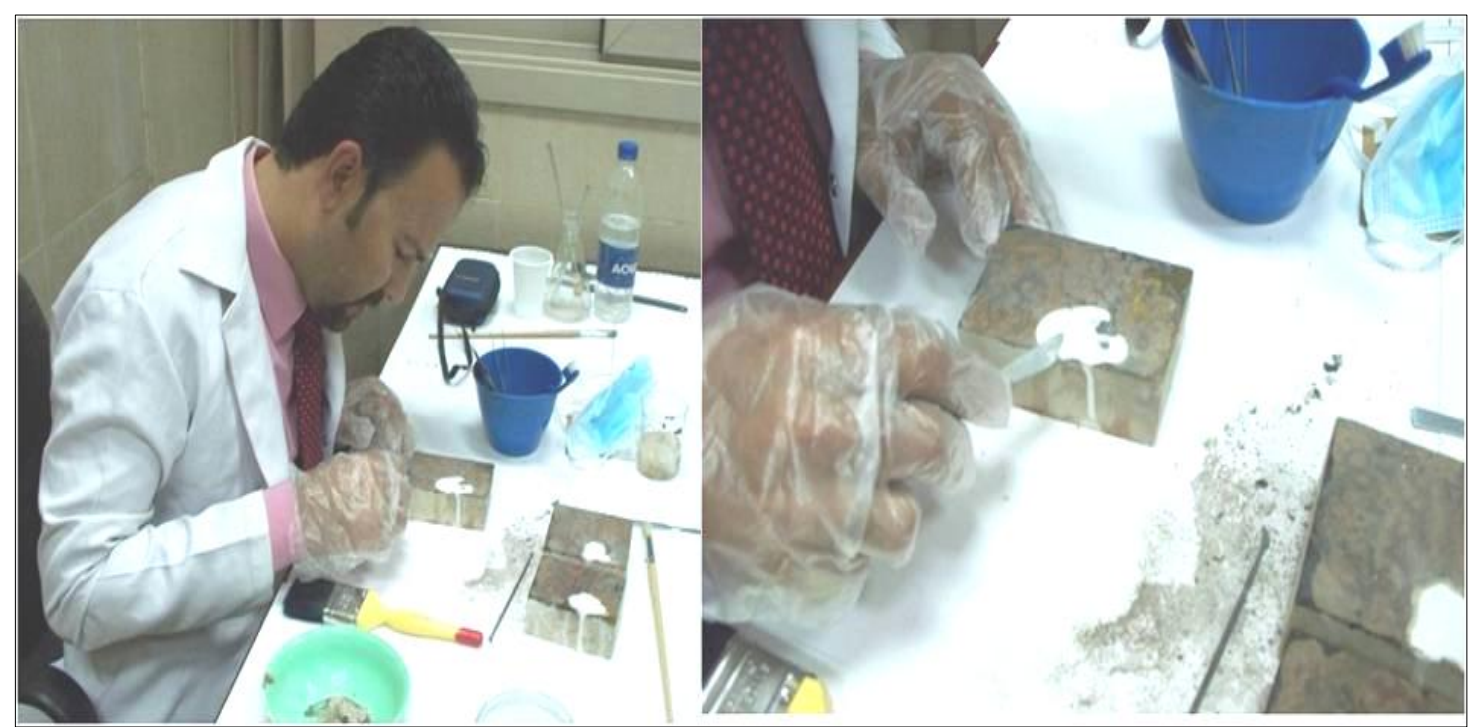

Figure (3) the wall painting models during the mechanical cleaning (No laser applied yet).

\subsubsection{Laser Cleaning}

Laser cleaning were performed with different irradiances according to the kind of encrustation layer of model. Various conditions of energy per pulse, no of shots and the distance between the lens and model were chosen to irradiate rectangle zone with different irradiance according to the encrustation layer. The cleaning of the model was done by focusing of the laser beam of the $\mathrm{Nd}$ :
YAG laser at 1064-nm via a quartz cylindrical lens of 9-cm focal length on the model. The model was positioned on the $x-y-z$ micro-translation stage. The emission from the plasma created during the removal of the encrustation layer was collected with fiber coupled to an Echelle spectrometer and ICCD camera system. The experimental setup is shown in fig. (4).

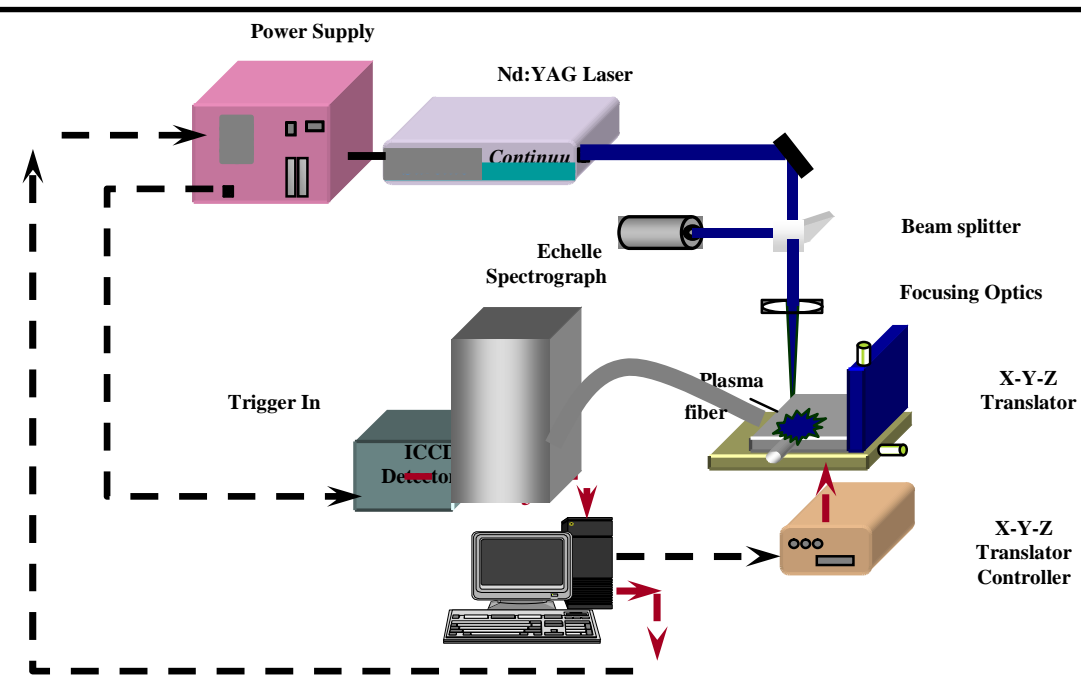

Figure (4) LIBS experimental setup. 
There were three experimental wall paintings models with different specific layers of deterioration aspects. The distance between the model and the lens was set to $7.5-\mathrm{cm}$ and the dimension of focused beam was $2 \times 7$ $\mathrm{mm}^{2}$ long. The whole parts of the model were cleaned at irradiance of 0.2 $\mathrm{J} \mathrm{cm}^{-2}$. The number of pulses was varying from one section to another according to thickness of layer need to be removed. The high numbers of pulses were used to remove thick crust layer while low number of pulses were used to remove the thin layer $(2 \mathrm{~Hz})$.
High irradiance of $1.2 \mathrm{~J} . \mathrm{cm}^{-2}$ was needed to remove layers of gypsum (10 $\mathrm{Hz}$ ), figs. (5 \& 6). The laser cleaning was very effective in cleaning the models but discoloration of the section of the yellow pigment "goethite FeOOH", [33] [36] [37] was noticed during the laser cleaning because of thermal effect of the $1064 \mathrm{~nm}$ laser beam. Though different laser wavelength of $532 \mathrm{~nm}$ was examined to avoid this discoloration but the same results were obtained. On the other hand no big difference was noticed for the three media used during laser cleaning, fig. (7).

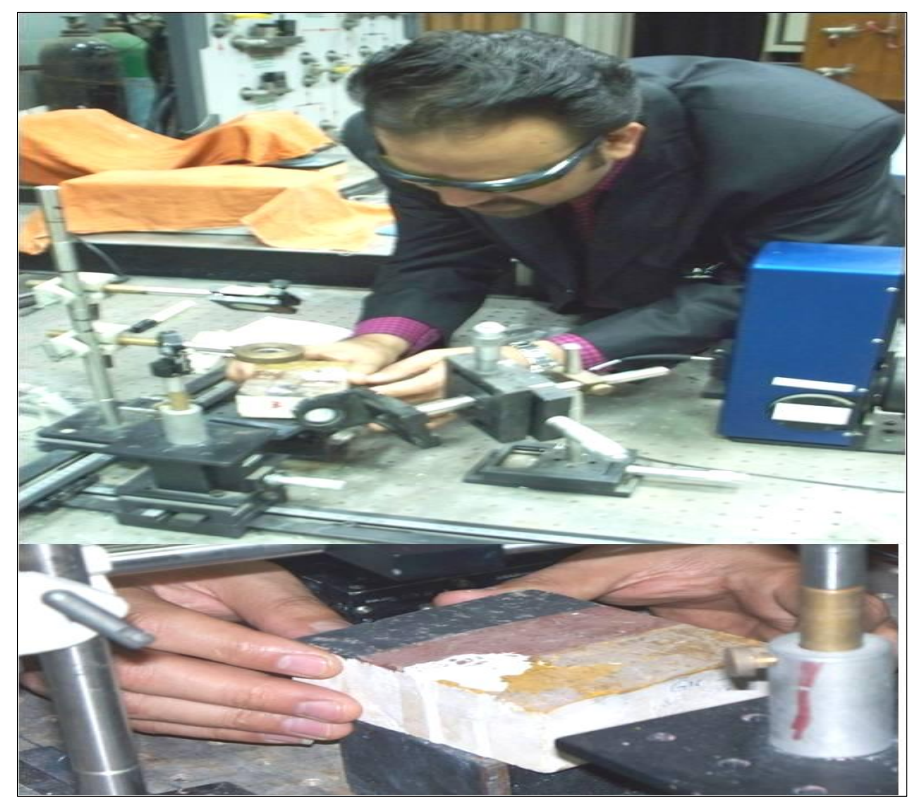

Figure (5) the wall painting models during laser cleaning, (notice the difficulty of gypsum incrustation removing).
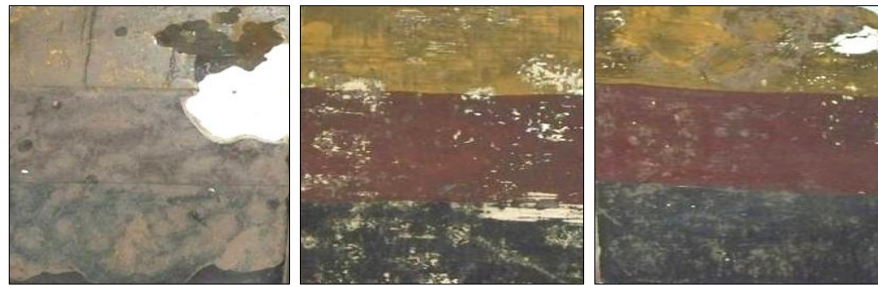

Figure (6) the wall painting models during laser cleaning compared with mechanical cleaning.

\section{Results of LIBS and discussion}

In order to assess the laser cleaning process, the LIBS has been used to monitor the emission spectra line of laser induced plasma during cleaning. Figure (8), shows cumulative LIBS spectra for the black pigment section of the wall painting before cleaning, during the removal of the dirt obtained for consecutive pulses and therefore provide an in depth profile for existing elements in the encrustation till it reached the original surface of the wall painting of the models. 

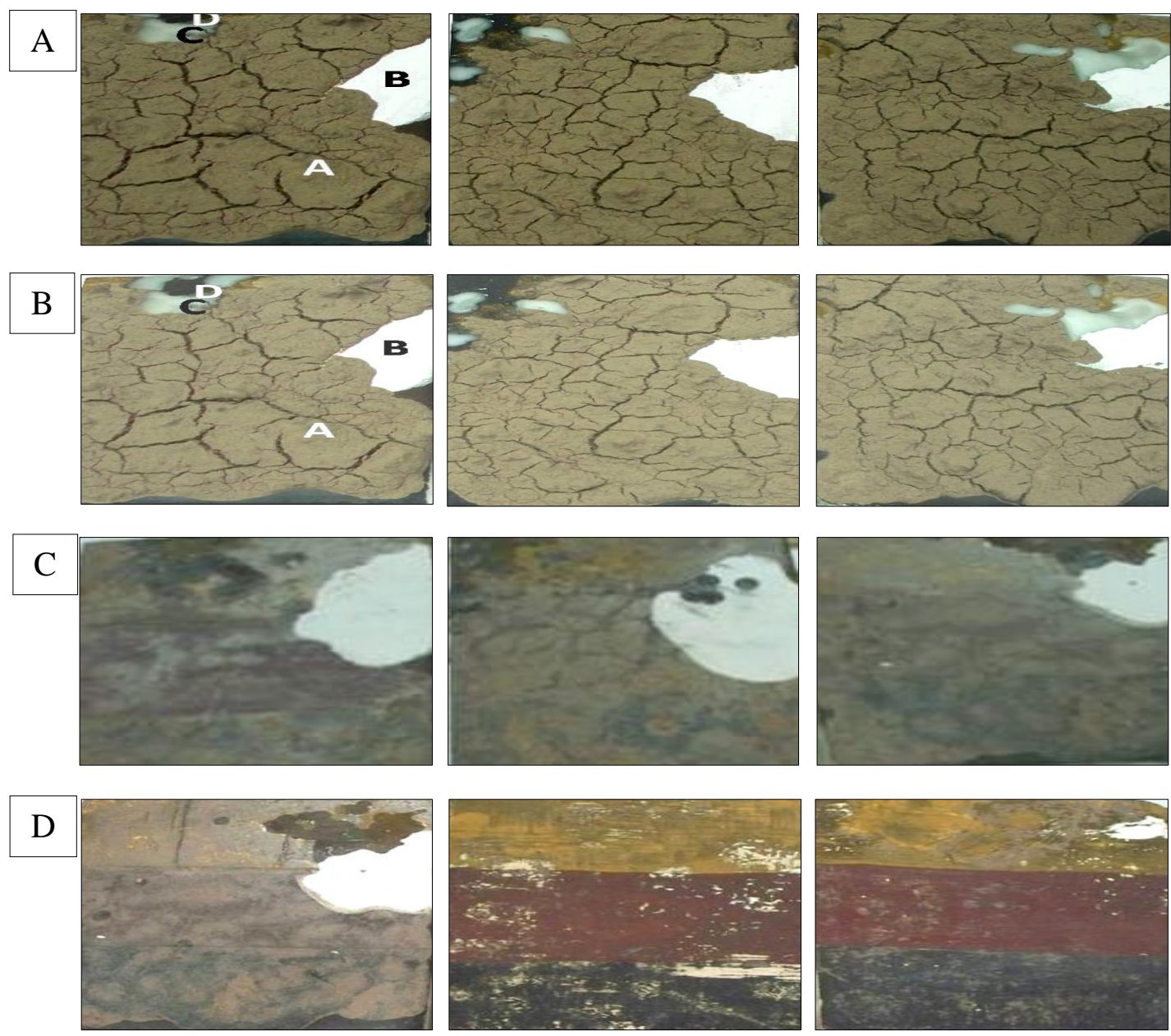

Figure (7) general photo show the wall painting models after adding the deterioration aspects (a) compared with the artificially ageing cycles (b), the mechanical cleaning (c), and Nd:YAG laser cleaning (d).

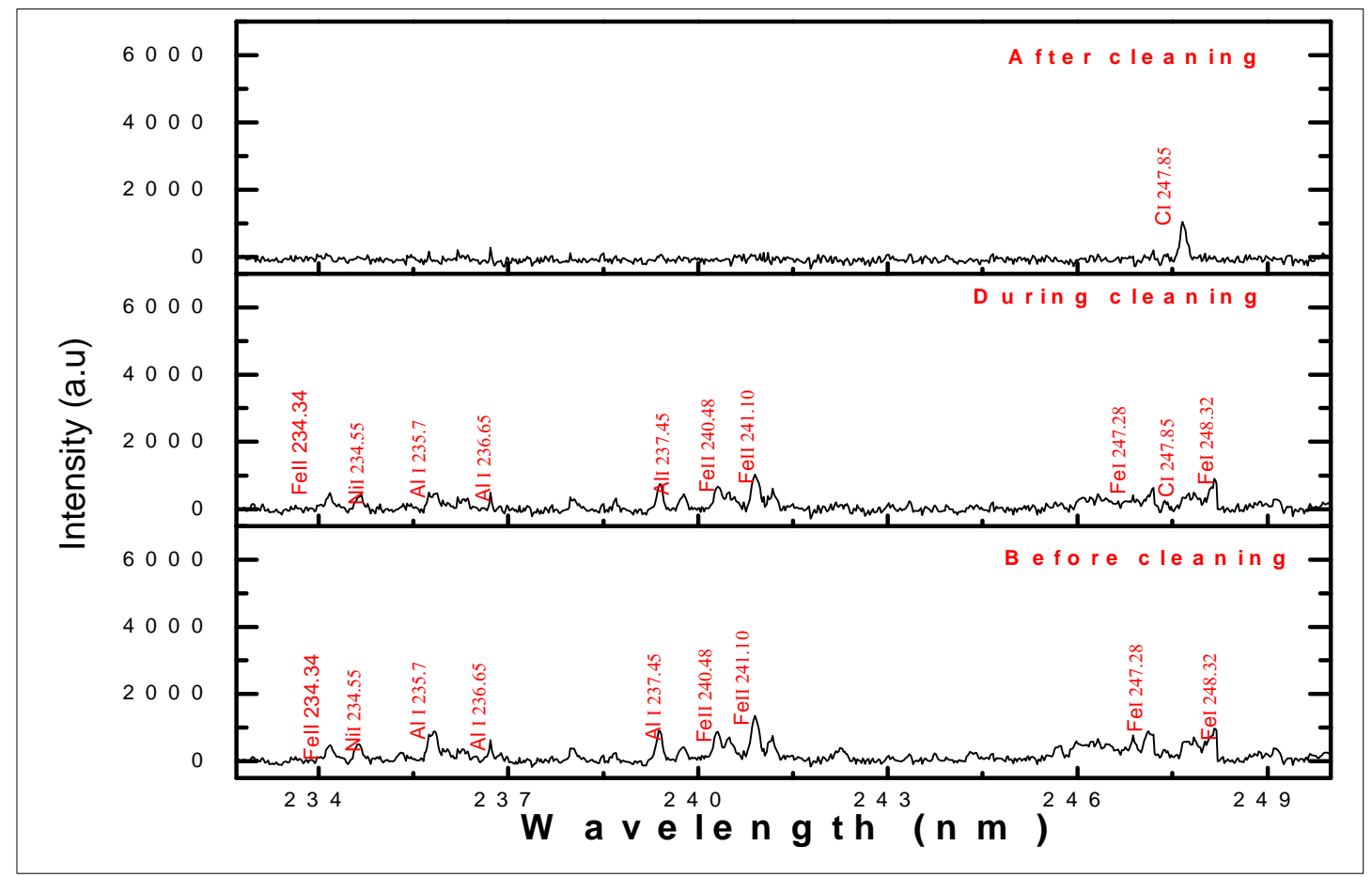

Figure (8) LIBS spectra of black pigment of the wall painting before, during and after laser cleaning. 
On one hand, fig (9) shows that $\mathrm{Al}, \mathrm{Fe}$, elements are the main components before laser cleaning, which are very rich in the deterioration aspects of the wall painting. While getting closer to the original surface the previous elements deceased during laser cleaning. On the other hand it completely disappeared after cleaning and $\mathrm{C}$ element was noticed as the only components, which representing the carbon black pigment. Those mean that we are on the original surfaces of the colored wall painting. According to the above data the successful removal of the layer of encrustations was achieved by monitoring the emission of $\mathrm{Al}, \mathrm{Fe}$ lines. When the emission of $\mathrm{Al}, \mathrm{Fe}$ disappeared and $\mathrm{C}$ emission exist, so we must stop the laser cleaning in this position and the $x-y-z$ stage moved to another one.

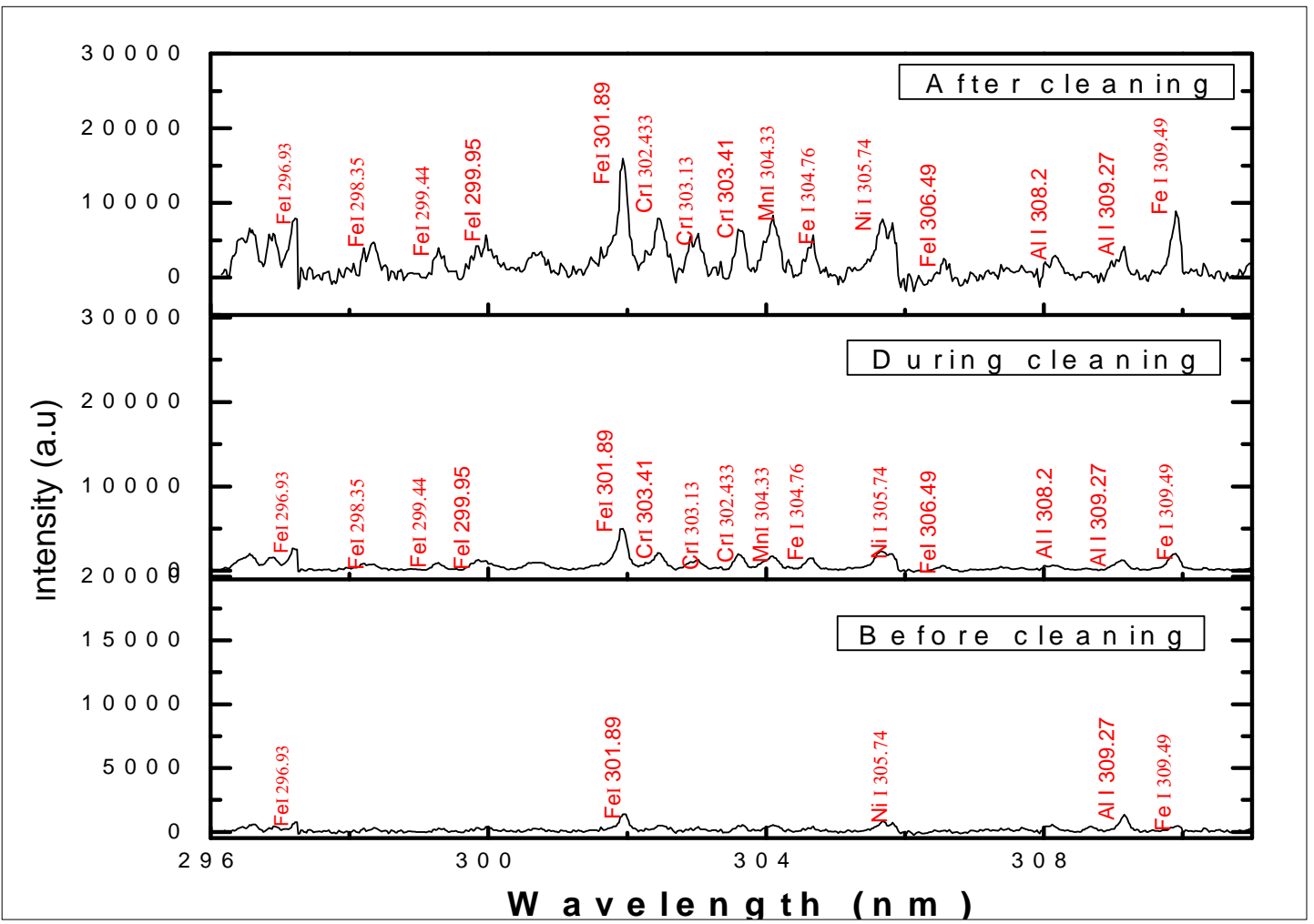

Figure (9) LIBS spectra of red pigment of the wall painting before, during and after laser cleaning.

From the previous data $\mathrm{Al}$, and $\mathrm{Ni}$ elements are the main components before laser cleaning, which are very rich in the deterioration aspects of the wall painting. While Fe presence, representing the red pigment in the model. By getting closer to the original surface $\mathrm{Al}$ element deceased during laser cleaning. On the other hand $\mathrm{Al}$ element decreased after cleaning and $\mathrm{Fe}$ and $\mathrm{Cr}$ elements were noticed as the components, which

Furthermore, fig. (10), shows on one hand cumulative LIBS spectra for yellow pigment section of the wall painting before cleaning, during the removal of the dirt obtained for representing the red pigment. Those mean that we are on the original surfaces of the colored wall painting. According to the above data the successful removal of the layer of encrustations was achieved by monitoring the emission of $\mathrm{Al}$, line. When the emission of $\mathrm{Al}$, decreased and Fe emission exist in a high intensity, so we must stop the laser cleaning in this position and the $x-y-z$ stage moved to another one.

consecutive pulses and therefore provide an in depth profile for existing elements in the encrustation till it reached the original surface of the wall painting of the models. 


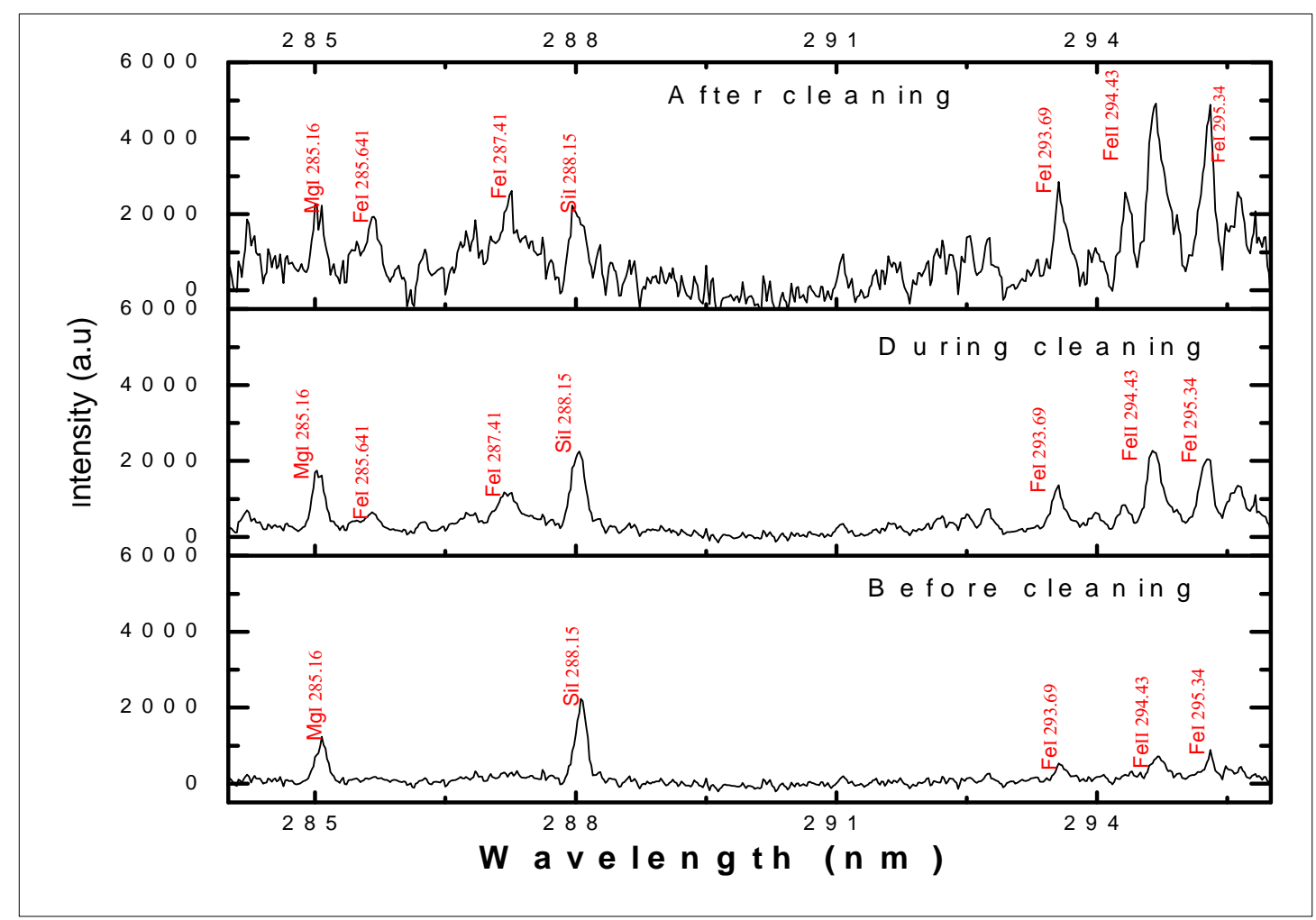

Figure (10) LIBS spectra of yellow pigment of the wall painting before, during and after laser cleaning.

From the previous data $\mathrm{Si}$, and $\mathrm{Mg}$ elements are the main components before laser cleaning, which are very rich in the deterioration aspects of the wall painting. While, $\mathrm{Fe}$ presence, representing the yellow pigment in the model. By getting closer to the original surface, Fe element increased during laser cleaning. On the other hand $\mathrm{Si}$, and $\mathrm{Mg}$ elements still there after cleaning which are consider as a contamination of the raw pigment. Those mean that we are on the original surfaces of the colored wall painting. According to the above data the successful removal of the layer of encrustations was achieved by monitoring the emission of $\mathrm{Fe}$, line. When the emission of Fe exist in a high intensity, so we must stop the laser cleaning in this position and the $x-y-z$ stage moved to another one. On the other hand discoloration was noticed during the laser cleaning because of thermal effect of the $1064 \mathrm{~nm}$ laser beam, though different laser wavelength of $532 \mathrm{~nm}$ was examined to avoid this discoloration but unfortunately the same results were obtained. The discoloration coming as a result of goethite $(\alpha-\mathrm{FeOOH})$ transformation into hematite $(\alpha-$ $\mathrm{Fe}_{2} \mathrm{O}_{3}$ )," dehydration or thermal dehydroxylation, [38][39]" occurring at about $300{ }^{\circ} \mathrm{C}$.,[40][41]. The thermal transformation from goethite to hematite can be described by the simple equation $" 2 \alpha-\mathrm{FeOOH}-\alpha-\mathrm{Fe}_{2} \mathrm{O}_{3}+$ $\mathrm{H}_{2} \mathrm{O}^{\prime \prime}$. On the other hand, the dehydration mechanism is much more complex and depends on the particle size of the goethite needles. Thermal behavior of this transformation was described as followed. In the beginning, surface auto diffusion played a dominant role. With increasing temperatures, micropores were produced due to three-dimensional diffusion of hydrogen or hydroxyl groups in bulk goethite crystals and then merged into the slits because of the high water pressure inside. The morphology of hematite particles with regular texture was changed due to the recrystalyzation role, and finally spherical particles were formed, [42], fig. (11). 


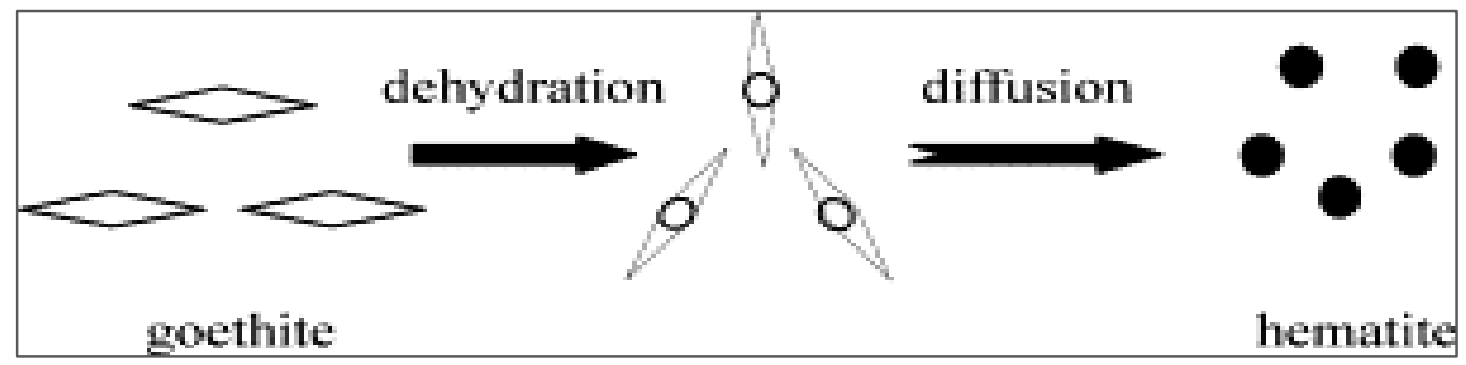

Figure (11) thermal behavior of goethite through three-dimensional diffusion (After, Fan H. et al., Thermal behavior of goethite...Materials Chemistry and PhysicsVolume 98, Issue 1 2006.).

Figure (12), shows cumulative LIBS spectra for red pigment section of the wall painting before cleaning, during the removal of gypsum encrustation, obtained for consecutive pulses and therefore provide an in depth profile for existing elements in the encrustation till it reached the original surface of the wall painting of the models. From the data shown in the previous figure, $\mathrm{Ca}$, element is the main components before laser cleaning, which are very rich in gypsum encrustation. While, getting closer to the original surface $\mathrm{Fe}$ element increased during laser cleaning, which represents the red pigment. On one hand $\mathrm{Ca}$, decreased during and after cleaning On the other hand $\mathrm{Fe}$ element increased during and after laser cleaning with a high intensity. Those mean that we are on the original surfaces of the colored wall painting. According to the above data the successful removal of the layer of encrustations was achieved by monitoring the emission of $\mathrm{Ca}, \mathrm{Fe}$, lines. When the emission of $\mathrm{Ca}$ element decreased and $\mathrm{Fe}$ emission exist in a high intensity, so we must stop the laser cleaning in this position and the $x-y-z$ stage moved to another one.

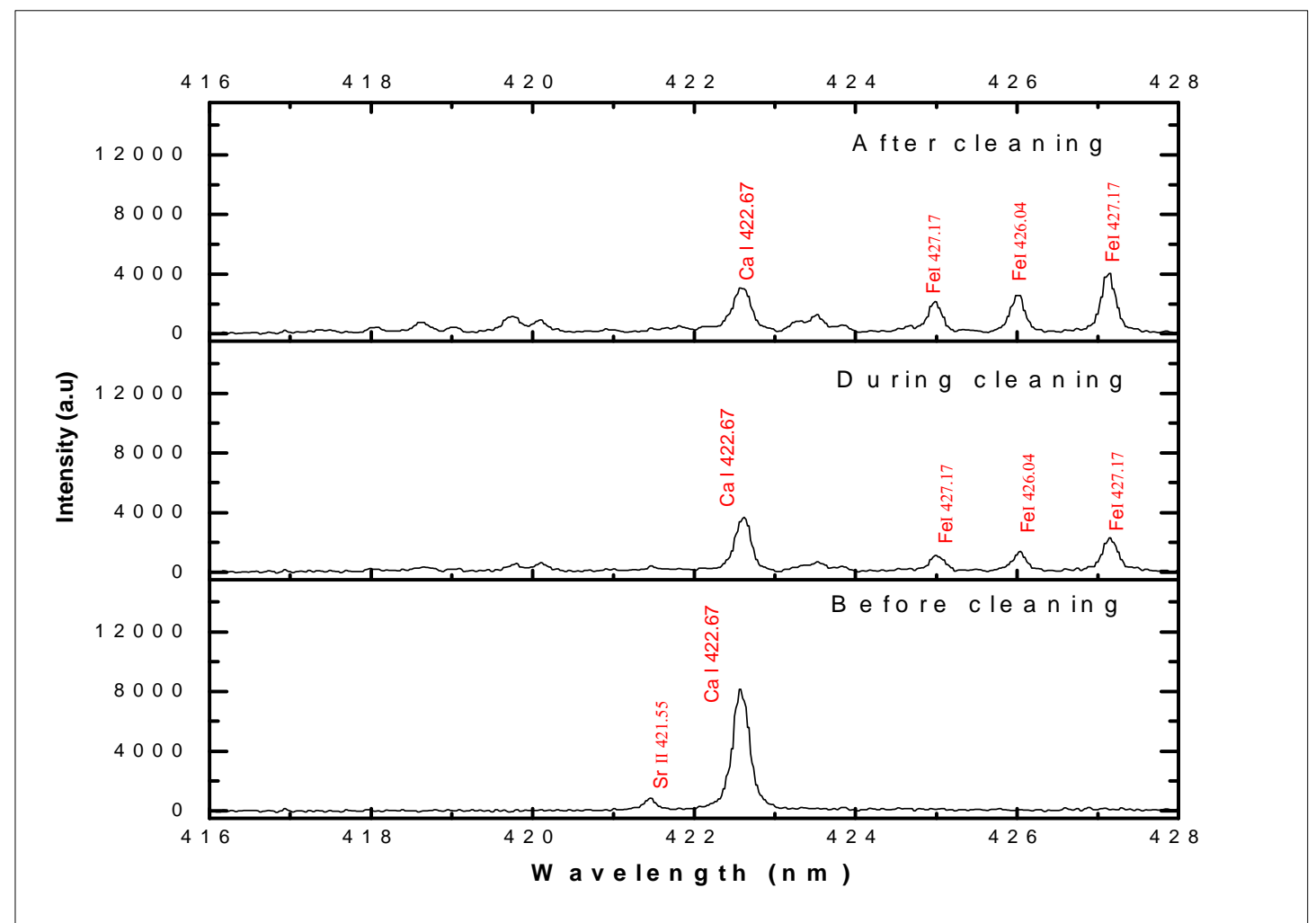

Figure (12) LIBS spectra of red pigment of the wall painting before, during and after gypsum removal by laser cleaning. 


\section{Conclusion}

Laser cleaning assessment of artificially prepared wall painting models was studied in this paper. Laser cleaning was performed with different irradiances according to the kind of encrustation layer of the model. Various conditions of energy per pulse, no of shots and the distance between the lens and model were chosen to irradiate rectangle zone with different irradiance according to the encrustation layer. The high numbers of pulses were used to remove thick crust layer while low number of pulses were used to remove the thin layer (2 $\mathrm{Hz}$ ). High irradiance of $1.2 \mathrm{~J} . \mathrm{cm}-2$ was needed to remove layers of Gypsum $(10 \mathrm{~Hz})$. The laser cleaning was very effective in cleaning the models but discoloration of the yellow pigment was noticed during the laser cleaning because of thermal effect of the $1064 \mathrm{~nm}$. laser beam. Though different laser wavelength of $532 \mathrm{~nm}$. was examined to avoid this discoloration but the same results were obtained. The discoloration, coming as a result of goethite ( $\alpha$ $\mathrm{FeOOH}$ ) transformation into hematite $\left(\alpha-\mathrm{Fe}_{2} \mathrm{O}_{3}\right)$ ", dehydration or thermal dehydroxylation. On the other hand no big difference was noticed for the three media used during laser cleaning. $A$ good compromise between fluence and the number of pulses always needs to be determined, and the use of laser for cleaning of wall paintings may be well complimented by other traditional methods for cleaning, as it is not always possible to completely remove surface dirt using laser ablation alone. Locally mechanical cleaning was applied before applying laser cleaning. Laser cleaning, with the aid of on-line LIBS monitoring, has been employed to remove extraneous encrustations of the wall painting models before and during cleaning. The removal obtained for consecutive pulses and therefore provides an in depth profile for existing elements in the encrustation till it reached the original surface of the wall painting of the models. On the other hand, it is impossible to specify optimal conditions for laser cleaning of the entire sections. In fact, tests illustrate the necessity to optimize laser cleaning for each type of area and the requirement to assess the cleaning results by using LIBS diagnosis.

Acknowledgement: The authors would like to thank Abdlaa Mahmoud, the assistant lecturer, faculty of archaeology, conservation dept., for his help in the model preparation.

\section{References}

[1] Georgiou S., Fotakis C., Anglos D., Zafiropulos V. and Tornari V., (2006). Lasers in the Preservation of Cultural Heritage: Principles and Applications Inst. of Physics Pub. Inc., Williston, Vermont.

[2] Calcagno G., Pummer E. and Koller M., (2000). St. Stephen's Church in Vienna: criteria for $\mathrm{Nd}$ : YAG laser cleaning on an architectural scale, J. Cultural Heritage, Vol. 1, (1), pp. 111-117.

[3] Weeks C., (1998). The Portail de la Mère Dieu of Amiens Cathedral: its polychromyand conservation, Studies in Conservation, Vol. 43, pp. 101-108.

[4] Pini R. Siano S., Salimbeni R., Piazza V., Giamello M., G. Sabatini G. and Bevilacqua F., (2000). Application of a new laser cleaning procedure to the mausoleum of Theodoric, J. Cultural Heritage, Vo1. pp. 93-97.

[5] Bromblet P., Labouri M. and Orial G., (2003). Diversity of the cleaning procedures including laser for the restoration of carved portals in France over the last 10 years, J. Cultural Heritage, Vol. 4, pp.1726.

[6] Siano S., Casciani A, Giusti A., M. Matteini M., Pini R., Porcinai S. and Salimbeni R., (2003). The Santi Quattro Coronati by Nanni di Banco: cleaning of the gilded decorations, J. Cultural Heritage, Vol., 4, (1) pp. 123 -128.

[7] Siano S. and Salimbeni R., (2001). The Gate of Paradise: physical optimization of the laser cleaning approach, Studies in Conservation, Vol. 46-269.

[8] Lee J. M. and Watkins K. G. (2000). In process and intelligent monitoring systems for laser cleaning process. Optics and Lasers in Engineering Vol. 34, (46) pp. 429-442 
[9] Klein, S., Hildenhagen, J., Dickmann, K., Stratoudaki, T. and Zafiropulos, V. (2000). LIBSSpectroscopy for Monitoring and Control of the Laser Cleaning Process of Stone and Medieval Glass. J. Cultural Heritage, Vol. 1, pp.287-292.

[10] Oujja, M., Rebollar, E., Castillejo, M., Domingo, C., Cirujano, C. and Guerra Librero, F. (2005). Laser Cleaning of Terracotta Decorations of the Portal of Palos of the Cathedral of Seville. $J$. Cultural Heritage, Vol. 6 (4) pp. 321-327.

[11] Lazic, V., Fantoni, R., Colao, F., Santagata, A., Morone, A. and Spizzichino, V. (2004). Quantitative Laser Induced Breakdown Spectroscopy Analysis of Ancient Marbles and Corrections for the Variability of Plasma Parameters and of Ablation Rate. J. Anal. At. Spectrom., Vol.19, pp. 429-436.

[12] Scholten, J.H., Teule, J.M., Zafiropulos, V. and Heeren, R.M.A. (2000). Controlled Laser Cleaning of Painted Artworks using Accurate Beam Manipulation and On-line LIBS-Detection. $J$. Cultural Heritage, Vol.1, pp. 215220.

[13] Bracco, P., Lanterna, G., Matteini, M., Nakahara, K. Sartiani, O., de Cruz, A. Wolbarsht, M.L., Adamkiewicz, E. and Colombini, M.P. (2003). Er: YAG Laser: An Innovative Tool for Controlled Cleaning of Old Paintings: Testing and Evaluation. $J$. Cultural Heritage, Vol. 4, pp. 202-208.

[14] Batishche, S., Englezis, A., Gorovets, T., Kouzmouk, A., Pilipenka, U., Pouli, P., Tatur, H., Totou, G. and Ukhau, V. (2005). Nd: YAG Laser Double Wavelength Ablation of Pollution
Encrustation on Marble and Bonding Glues on Duplicated Painting Canvas. Appl. Surf. Sci., Vol. 248, pp.264-269.

[15] Pouli, P., Nevin, A., Andreotti, A., Colombini, P., Georgiou, S. and Fotakis, C. (2009). Laser Assisted Removal of Synthetic PaintingConservation Materials using UV Radiation of ns and fs Pulse Duration: Morphological Studies on Model Samples. Appl. Surf. Sci., Vol. 255, pp.4955-4960.

[16] Teule, R., Scholten, H., van den Brink, O.F., Heeren, R.M.A., Zafiropulos, V., Hesterman, R., Castillejo, M., Martin, M., Ullenius, U., Larsson, I., GuerraLibrero, F., Silva, A., Gouveia, H. and Albuquerque, M.-B. (2003). Controlled UV Laser Cleaning of Painted Artworks: A Systematic Effect Study on Egg Tempera Paint Samples. J. Cultural Heritage, Vol. 4, pp.209-215.

[17] Lopez, A.J., Nicolas, G., Mateo, M.P., Pinon, V., Tobar, M.J. and Ramil, A. (2005). Compositional Analysis of Hispanic Terra Sigillata by Laser-induced Breakdown Spectroscopy., Spectrochim. Acta B, Vol. 60, pp.1149-1154.

[18] Lopez, A.J., Nicolas, G., Mateo, M.P., Ramil, A., Pinon, V. and Yanez, A. (2006). LIPS and Linear Correlation Analysis Applied to the Classification of Roman Pottery Terra Sigillata., Appl. Phys. A, Vol. 83, pp. 695698.

[19] Colao, F., Fantoni, R., Lazic, V. and Spizzichino, V. (2002). Laserinduced Breakdown Spectroscopy for semi-Quantitative and Quantitative Analyses of Artworks-Application on multiLayered Ceramics and Copper based Alloys, Spectrochim. Acta B, Vol.57, pp. 1219-1234. 
[20] Fortes, F.J., Cabalín, L.M. and Laserna, J.J. (2008). The Potential of Laser-induced Breakdown Spectrometry for Real Time Monitoring the Laser Cleaning of Archaeometallurgical Objects. Spectrochim. Acta, B, Vol. 63, pp. 1191-1197.

[21] Ochocińska, K., Kamińska, A. and Sliwinski, G. (2003). Experimental Investigations of Stained Paper Documents Cleaned by the Nd: YAG Laser Pulses. $J$. Cultural Heritage, Vol. 4, 188193.

[22] Kaminska, A., Sawczak, M., Komar, K. and Sliwinski, G. (2007). Application of the Laser Ablation for Conservation of Historical Paper Documents. Appl. Surf. Sci., Vol. 253, pp. 7860-7864.

[23] Gronlund, R., Lunqvist, M. and Svanberg, S. (2005) Remote Imaging Laser-induced Breakdown Spectroscopy and Remote Cultural Heritage Ablative Cleaning. Opt. Lett., Vol.30, pp. 2882-2884.

[24] Vazquez-Calvo, C., Giakoumaki, A., Anglos, D., Alvarez de Buergo, M. and Fort, R. (2007). Classification of Patinas Found on Surfaces of Historical Buildings by Means of Laser-induced Breakdown Spectroscopy. In Lasers in the Conservation of Artworks, Springer: Berlin, Germany, Vol. 116, pp.415-420.

[25] Osticioli, I., Mendes, N.F.C., Porcinai, S., Cagnini, A. and Castellucci, E. (2009). Spectroscopic Analysis of Works of Art using A Single LIBS and Pulsed Raman Setup. An al. Bioanal. Chem., Vol.394, pp.1033-1041.

[26] Burgio, L., Melessanaki, K., Doulgeridis, M., Clark, R.J.H. and Anglos, D. (2001). Pigment Identification in Paintings Employing Laser Induced
Breakdown Spectroscopy and Raman Microscopy, Spectrochim. Acta B., 56 (6) pp. 905-913.

[27] Clark, R.J.H. (2002) Pigment Identification by Spectroscopic Means: An Arts/Science Interface. C. R. Chim., Vol. 5, pp. 7-20.

[28] Brysbaert, A., Melessanaki, K. and Anglos, D. (2006). Pigment Analysis in Bronze Age Aegean and Eastern Mediterranean Painted Plaster by Laser-induced Breakdown Spectroscopy (LIBS). J. Archaeol. Sci., Vol.33, pp. 10951104.

[29] Castillejo, M., Martin, M., Silva, D., Stratoudaki, T., Anglos, D., Burgio, L. and Clark, R.J.H. (2000). Analysis of Pigments in Polychromes by Use of Laser Induced Breakdown Spectroscopy and Raman Microscopy. J. Mol. Struct., Vol.550, pp.191-198.

[30] Oujja, M., Vila, A., Rebollar, E., Garcia, J.F. and Castillejo, M. (2005). Identification of Inks and Structural Characterization of Contemporary Artistic Prints by Laser-induced Breakdown Spectroscopy, Spectrochim. Acta B, Vol. 60, pp.1140-1148.

[31] Bruder, R., L'Hermite, D., Semerok, A., Salmon, L. and Detalle, V. (2007). Near-Crater Discoloration of White Lead in Wall Paintings During Laser Induced Breakdown Spectroscopy Analysis, Spectrochim. Acta B, Vol. 62, pp. 1590-1596.

[32] Dolgin, B., Chen, Y., Bulatov, V., and Schechter, I. (2006). Use of LIBS for Rapid Characterization of Parchment. Anal. Bioanal. Chem., Vol.386, pp.1535-1541.

[33] Uda M., Sassa S., Yoshimura S., Kondo J., Nakamura M., Ban Y. and Adachi H.(2000). Yellow, red and blue pigments from ancient Egyptian palace painted walls, Nuclear Instruments and Methods in Physics Research B Vol., 161163, pp. $758-761$ 
[34] Alessandra P., Lorenzo A. and Piero M. (2003) Non-destructive in situ determination of pigments in $15^{\text {th }}$ century wall paintings by Raman microscopy, Analytica Chimica Acta, Vol. 480, (2) pp.317-325

[35] Norvaisiene R., Burlingis A. and Stankevicius V., (2010). Durability tests on painted facade rendering by accelerated ageing, Materials science (Medziagotyra). Vol. 16 (1) pp.80-85.

[36] Danilo B., Gianni A., Pier P. L. and Antonella C. (2003). Raman microspectrometric investigation of wall paintings in: a comparison between two artists of the $16^{\text {th }}$ century, Spectrochimica Acta Part A: Molecular and Biomolecular Spectroscopy, Vol. 59 (10) pp. 2409-2417.

[37] Uda, M. (2004). In situ characterization of ancient plaster and pigments on tomb walls in Egypt using energy dispersive $\mathrm{X}$ ray diffraction and fluorescence, Nuclear Instruments and Methods in Physics Research Section B: Beam Interactions with Materials and Atoms, Vol. 226 (1-2) pp.7582.

[38] Walter, D., Buxbaum G. and Laqua W. (2001). The Mechanism of the Thermal Transformation from Goethite to Hematite, Journal of Thermal Analysis and Calorimetry, Vol. 63 (3) pp.733748.

[39] Ruan H. D., Frost R. L., Kloprogge J. T. and Duong L. (2002). Infrared spectroscopy of goethite dehydroxylation: III. FTIR microscopy of in situ study of the thermal transformation of goethite to hematite, Spectrochimica Acta Part A: Molecular and Biomolecular Spectroscopy Vol. 58, (5), pp. 967-981.

[40] Fan H., Song B. and Li Q. (2006) Thermal behavior of goethite during transformation to hematite, Materials Chemistry and Physics, Vol. 98 (1) pp. 148-153.

[41] Diamandescu, L MihàilàTàràbàşanu $\mathrm{D}$. and Feder $\mathrm{M}$. (1993). On the solid phase transformation goethite $\rightarrow$ hematite, $\quad$ Materials Letters, Vol.17 (5), pp. 309-311.

[42] González G., Amaya Sagarzazu A. and Villalba R. (2000). Study of the mechano-chemical transformation of goethite to hematite by TEM and XRD, Materials Research Bulletin, Vol. 35 (14-15), pp.2295-2308 